\title{
GRAPHEN-PHENYL-NH 2 AS NANOCARRIER: A DENSITY FUNCTIONAL THEORY STUDY
}

\author{
Nosrat Madadi Mahania*, ${ }^{*}$, Fatemeh Mostaghni ${ }^{a}$ and Homa Shafiekhani ${ }^{a}$ \\ aDepartment of Chemistry, Payame Noor University (PNU), 19395-4697 Tehran, Iran
}

Recebido em 02/10/2021; aceito em 13/12/2021; publicado na web em 16/02/2022

\begin{abstract}
Recently, graphene and modified graphene as one of the most suitable and the most important carbon nanomaterials have been introduced for drug delivery. In this paper, we have studied the binding characteristics of the EDC-NHS cross-linking process of graphene-phenyl- $\mathrm{NH}_{2}$ and 5-aminolevulinic acid (ALA) drug in both gas and solvent phases by density functional theory calculations. For describing binding properties and reaction nature between graphene-ghenyl- $\mathrm{NH}_{2}$ and ALA drug, quantum molecular descriptors, topological analysis, natural bond orbital analysis, analysis of the bond order, the density of states, and analysis bond length was investigated in solvent and gas phases. Due to the results, the complex of the graphene-phenyl- $\mathrm{NH}_{2} @$ ALA turns to absorb more electrons in water solvent than gas phase. Furthermore, the binding of graphene-phenyl- $\mathrm{NH}_{2}$ and ALA is mainly based on covalent interactions, and bond order of graphene-phenyl- $\mathrm{NH}_{2} @$ ALA complex is one in solvent and gas phases. The praphene-phenyl$\mathrm{NH}_{2} @$ ALA complex has displayed a meaningful improvement of electronic and structural properties. Therefore, it represented that praphene-phenyl- $\mathrm{NH}_{2}$ being combined with the ALA drug is appropriate for use in drug delivery.
\end{abstract}

Keywords: graphene-Phenyl- $\mathrm{NH}_{2} ; 5$-aminolevulinic acid drug; density functional theory; natural bond orbital analysis; topological analysis.

\section{INTRODUCTION}

Using the nanocarriers of anticancer drugs like micelles, liposomes, solid lipid nanoparticles, nanocages, carbon nanotubes, nanocrystals, and graphene oxide indicated an appropriate therapy of cancer by targeting specific cells of the tumor and these nanocarriers have no side effects. ${ }^{1-5}$ Drug delivery systems basis on the nanoscale to causes releasing on time and in place target of drug molecule. ${ }^{6}$ Also, drug nanocarriers can reduce drug toxicity. ${ }^{7}$ They provide modifications such as biocompatibility, half-life, solubility, and its release characteristics in properties of drug. ${ }^{8}$

Nanostructures as graphene sheets due to having properties such as light-weight, electron transport, structural strength, biocompatibility, flexibility, and having an extensive surface for double face adsorption in two dimensions can be used as sensor, cellular imaging, drug delivery and gene delivery agents. ${ }^{910}$ Graphene sheets are valuable for drug delivery due to solubility, and stability in the biological environment. ${ }^{9}$

Recently, researchers have displayed which graphene-phenyl- $\mathrm{NH}_{2}$ have cytoprotective properties. ${ }^{11}$ Graphene-phenyl- $\mathrm{NH}_{2}$ is the securest graphene derivative because it is not endowed with hemolytic and thrombotic properties in comparison to other graphene derivatives ${ }^{12}$ and is therefore can be used in biomedicine applications. Also, The edges and defect sites are well known to be more reactive than the basal plane of graphene. Therefore, the phenyl- $\mathrm{NH}_{2}$ group onto the zigzag egde is much more reactive than the central part of graphene. ${ }^{13}$

5-Aminolevulinic acid (ALA) is a prodrug that is used in photodynamic therapy in treating non-melanoma skin cancers due to its bioavailability. ${ }^{14,15}$ ALA has two active sites which include the carboxylic acid group and the amine group which the O-side of the carboxylic acid group can be covalently binding to graphene-phenyl$\mathrm{NH}_{2}$. In the present study, the bonding of $\mathrm{G}-\mathrm{NH}_{2}$ with the ALA drug was theoretically investigated. The bond between graphenephenyl- $\mathrm{NH}_{2}$ with ALA drugs was appointed through a cross-linking compound that is correlated to the creating of amides bond betwixt

*e-mail: nmmadady@gmail.com drug and graphene-phenyl- $\mathrm{NH}_{2}$. This study aims to access the information about electronic characteristics, the natural electronic configurations by natural bond orbital analysis, chemical bond nature due to the topological analysis of electron density, the bond order analysis due to the laplacian electron density of the reaction of graphene-Phenyl- $\mathrm{NH}_{2}$ and ALA drug applying density functional theory computational method.

The interaction of ALA with SWCNTs $(5,5)$ and (9, 0), C24 and $\mathrm{C} 60$ has been studied with hybrid density functional theory calculations. ${ }^{16} \mathrm{Ab}$ initio calculations for investigation the electronic and structural properties of ALA functionalized BNNTs have been performed by Samanata et al..$^{17}$

Adsorption of cytarabine, ${ }^{18}$ ampyra,,${ }^{19}$ tegafur, ${ }^{20}$ and cladribine ${ }^{21}$ drugs anticancer on the graphene, and functionalized graphene as nanocarriers systems have been investigated using DFT calculations. Investigation binding of Doxorubicin drug with the graphene and functionalized graphene have been done using density functional theory computational by Vovusha et al..22 A theoretical study on the reactivity and the structural properties of the Melphalan anticancer drug with PAMAM dendrimer was done in both phases of gas and solvent. $^{23}$

The addition of aryl radicals to perfect and defective graphene has been studied by dispersion-corrected density functional theory. ${ }^{24}$ Also, dispersion-corrected density functional theory has been utilized to study the interaction between alkyl radicals and graphene. ${ }^{25}$ Cycloadditions reactions onto grapheme like the $[2+2]$ cycloadditions, ${ }^{26}$ Diels-Alder, ${ }^{27}[6+4]$ cycloadditions ${ }^{28}$ and, heteroatom promoted cycloaddition ${ }^{29}$ have been studied by means of density functional theory. Our study's results can help a better viewpoint of the reaction between graphene-phenyl- $\mathrm{NH}_{2}$ and ALA drug and proper information about the bonding of the reaction between graphene-phenyl- $\mathrm{NH}_{2}$ with ALA drug.

\section{METHODS}

At first, we applied GAUSSIAN 09 package $^{30}$ to optimize all structures and quantum chemical computations in the solution and gas 
phases at Becke's three-parameter Lee-Yang-Parr hybrid functional ${ }^{31}$ with 6-311G basis set. density functional theory computations present us excellent viewpoints into structural geometry changes, interaction energy, and load distribution in the encapsulation process. Frequency computations are done to remove the imaginary frequencies and gaining minimum energy. Quantum theory of atoms in molecules and multifunctional wavefunction analyzer ${ }^{32}$ are applied to investigate the nature of interaction and binding among the atoms of graphene-phenyl$\mathrm{NH}_{2}$ and ALA by the topological analysis of the electron densities. Moreover, Fuzzy bond order, ${ }^{33}$ Mayer bond order, ${ }^{34}$ and natural bond orbital (NBO) for graphene-phenyl- $\mathrm{NH}_{2} @$ ALA were calculated.

Besides, the function of electron localization as a measurement of the likelihood of finding an electron in the neighborhood space of a reference electron located at a given point and with the same $\operatorname{spin}^{35} \mathrm{was}$ achieved by Multiwfn code. For simulating the biological system, configurations are surveyed in the solvent phase. Surveying solvent impacts was done using the integral equation formalism polarized continuum model of self-consistent reaction field. ${ }^{36}$ The descriptors of quantum chemical as an energy gap, and electronegativity and global hardness can be used to assess the chemical reactivity which is computed. The bond between graphene-phenyl- $\mathrm{NH}_{2}$ and ALA is made by a cross-linking applying EDC-NHS.

The final reaction between the ALA drug and graphene-phenyl$\mathrm{NH}_{2}$ can be written as follows:

$$
A L A+\text { graphene }- \text { phenyl }-\mathrm{NH}_{2} \stackrel{\text { EDCNHS }}{\longrightarrow} \text { graphene-phenyl }-\mathrm{NH}_{2} @ \text { ALA }+\mathrm{H}_{2} \mathrm{O}
$$

The bonding energies resulting from the reaction between the graphene-phenyl- $\mathrm{NH}_{2}$ and ALA can be acquired from equation (2).

$$
\Delta X_{\text {binding }}=\left(X_{\text {complex }}+X_{\mathrm{H}_{2} \mathrm{O}}\right)-\left(X_{A L A}+X_{\mathrm{G}_{\mathrm{NH}} \mathrm{H}_{2}}\right)
$$

where $\mathrm{X}$ is the enthalpy $(\mathrm{H})$, the Gibbs free energy $(\mathrm{G})$ or total energy (E), and $\mathrm{X}_{\text {complex }}$ is corresponds to the values of the graphene-phenyl$\mathrm{NH}_{2} @$ ALA.

\section{RESULTS AND DISCUSSION}

We have firstly optimized the structures of graphene-phenyl- $\mathrm{NH}_{2}$ and ALA in gas and solvent phases. The geometrically optimized structures of graphene-phenyl- $\mathrm{NH}_{2}$ and ALA in the solvent phase were shown in Figure 1. Moreover, the optimized configurations of graphene-phenyl- $\mathrm{NH}_{2} @$ ALA in the solvent phase were indicated in Figure 2.

(a)
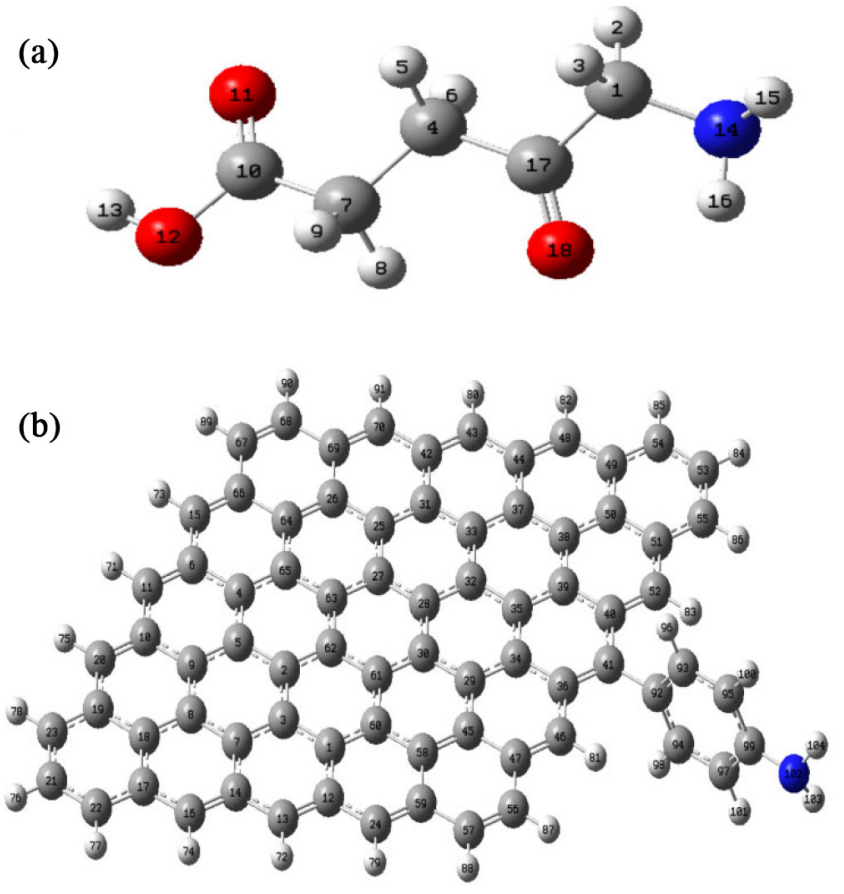

Figure 1. The optimized configurations of the ALA (a), and G-Phenyl-NH (b) at the solvent phase

The chemical reactivity descriptors of ALA, graphene-phenyl$\mathrm{NH}_{2}$ and ALA@graphene-phenyl- $\mathrm{NH}_{2}$ have shown in Table 1. The global hardness and the energy gap of ALA in the solvent phase is less than in the gas phase. Therefore, the stability of ALA is less in the water solvent and its reactivity is higher. The global hardness and energy gap of graphene-phenyl- $\mathrm{NH}_{2}$ in the solvent phase is greater than in the gas phase. After binding, the energy gap and global hardness of the ALA@graphene-phenyl- $\mathrm{NH}_{2}$ complex decreased

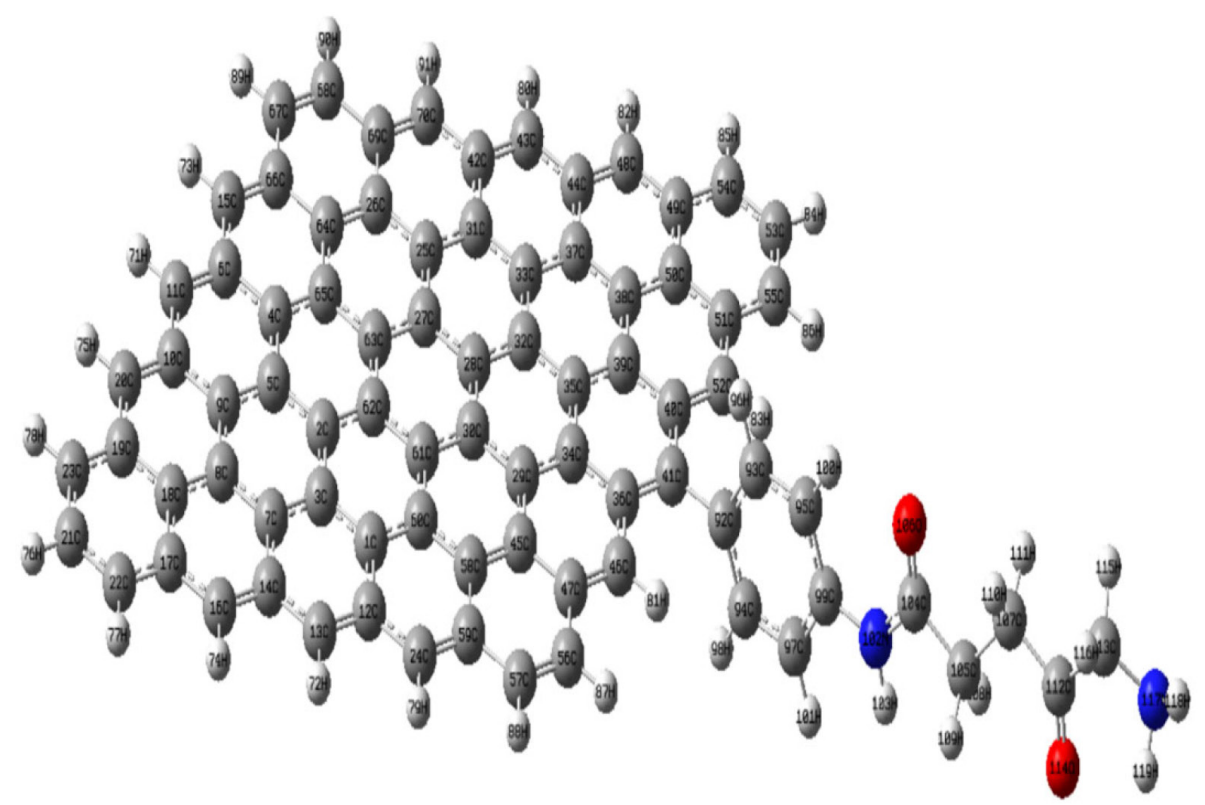

Figure 2. The optimized configurations of the ALA@G-Phenyl-NH $\mathrm{H}_{2}$ at the solvent phase 
Table 1. The gap energy, global hardness, and electronegativity (eV) for G- $\mathrm{NH}_{2}$, ALA and ALA@ G-Phenyl- $\mathrm{NH}_{2}$

\begin{tabular}{|c|c|c|c|c|c|c|}
\hline \multirow[t]{2}{*}{ Compound } & \multicolumn{2}{|c|}{$\mathrm{E}_{\mathrm{g}}=\mathrm{E}_{\text {LUмо }}-\mathrm{E}_{\text {номо }}$} & \multicolumn{2}{|c|}{$\mathrm{X}=-\left(\mathrm{E}_{\text {номо }}+\mathrm{E}_{\text {LUмо }}\right) / 2$} & \multicolumn{2}{|c|}{$\eta=E_{g} / 2$} \\
\hline & Gas & Solvent & Gas & Solvent & Gas & Solvent \\
\hline G-NH ${ }_{2}$ & 0.6320 & 2.3473 & 3.5157 & 3.8849 & 0.3160 & 1.1736 \\
\hline ALA & 5.7396 & 6.0449 & 3.4927 & 3.5702 & 2.8698 & 3.0249 \\
\hline ALA@G-NH & 0.6770 & 1.9763 & 3.6133 & 3.9589 & 0.3385 & 0.9881 \\
\hline
\end{tabular}

compared to pristine ALA in the solvent phase and electronegativity increased compared to ALA in the water solvent.

By surveying the electronegativity, it can be understood that graphene-phenyl- $\mathrm{NH}_{2}$ turn to absorb more electron than solvent phase. Therefore, the reaction of ALA and graphene-phenyl- $\mathrm{NH}_{2}$ causes an increase in the electronegativity and reduced their energy gap and global hardness in the solvent phase. The reaction energies of ALA and graphene-phenyl- $\mathrm{NH}_{2}$ in both phases are indicated in Table 2. In the ALA@ graphene-phenyl- $\mathrm{NH}_{2}$ system, Gibbs free energies are negative which shows the adsorption is spontaneous. Moreover, the negative enthalpies indicated that this reaction is exothermic. Furthermore, the polarity of molecules is shown by the dipole moment. The polarity of ALA@ graphene-phenyl- $\mathrm{NH}_{2}$ is higher in water solvent than in the gas phase.

Table 2. The binding, the enthalpy, the Gibbs free energies, and dipole moment for ALA@ G-Phenyl-NH

\begin{tabular}{ccc}
\hline $\begin{array}{c}\text { Energies and dipole } \\
\text { moment }\end{array}$ & Gas & Solvent \\
\hline$\Delta \mathrm{E}((\mathrm{kJ} / \mathrm{mol})$ & -31.7024 & -35.0739 \\
$\Delta \mathrm{G}(\mathrm{kJ} / \mathrm{mol})$ & -28.7610 & -30.0016 \\
$\Delta \mathrm{H}(\mathrm{kJ} / \mathrm{mol})$ & -33.1312 & -37.5078 \\
$\mu($ Debye $)$ & 3.7854 & 5.2098 \\
\hline
\end{tabular}

Grimme has taken a different approach for correction of free energy based on the rigid rotor-harmonic oscillator (RRHO) approximation $^{37}$ by arguing that low-frequency modes resemble free rotations and using the corresponding entropy term for low frequency modes. The free energy of association of molecules A and $\mathrm{B}$ to form a bound complex $\mathrm{C}$, at temperature $\mathrm{T}$ in solvent $\mathrm{X}$ is given by equation 3 :

$$
\Delta G_{a}=\Delta E_{\text {gas }}+\Delta G_{R R H O}^{T}+\Delta \delta G_{\text {solv }}^{T}(X)
$$

which $\Delta E$ is different in energies of complex and reactants in the gas phase, $\Delta G_{R R H O}^{T}$ is the sum of corrections from energy to free energy in the rigid-rotor-harmonic-oscillator approximation (RRHO) also including zero-point-vibrational energy for each species in the gas phase, and $\Delta \delta G_{\text {solv }}^{T}$ is their corresponding free solvation free energy. Based on equation 3, $\Delta E_{\text {gas }}=-31.7024, \Delta \delta G_{\text {solv }}^{T}(X)=-4.3767$ and, $\Delta G_{R R H O}^{T}=1.0905 \mathrm{~kJ} \mathrm{~mol}^{-1}$, therefore $\Delta G_{a}=-34.9886 \mathrm{~kJ} \mathrm{~mol}^{-1}$ which illustrated value of free energy in the phase condensed.

The saddle point on distributing electron density is named bond critical point which has the electron density gradient of zero. The bond critical point (BCP) is a first-order saddle point in the electron density distribution. The bond critical point is described by the major diameter elements of the Hessian matrix of electron density. The laplacian of the electron density is the trace of the Hessian matrix and the sum of the diagonal elements of the second derivative matrix of the density at a point is the Laplacian of electron density at that point. ${ }^{38}$ In regions where the Laplacian is negative, the potential energy is dominant and the negative charge is concentrated and, in regions where the Laplacian is positive, the kinetic energy density dominates and a depletion of negative charge occurs.

At bond critical point (BCP), quantities as the Laplacian, $\nabla^{2} \rho(r)$, the potential energy density, $\mathrm{V}(\mathrm{r})$, the positive definite kinetic energy density, $\mathrm{G}(\mathrm{r})$, and the total electronic energy density, $\mathrm{H}(\mathrm{r})=\mathrm{V}(\mathrm{r})+\mathrm{G}(\mathrm{r})$, in terms of which the bond degree, $\mathrm{H}(\mathrm{r}) / \rho(\mathrm{r})$, can be deliberated. In addition, equation 4 , displays a helpful relationship between them:

$$
E(r)=\frac{1}{4} \nabla^{2} \rho(r)-G(r)=V(r)+G(r)
$$

The nature of chemical bonds could be distinguished by the values of potential and kinetic energy. The characteristics of chemical bonds can be shown by the amounts of potential and kinetic energy. The chemical bonds is covalent in case Laplacian and $\mathrm{V}(\mathrm{r})$ be negative, $\rho(r)>0.02, G(r) / \rho(r)$ and $G(r) / V(r)<1 .{ }^{39}$ Ionic interactions displays positive Laplacian and $\mathrm{V}(\mathrm{r}), \rho(\mathrm{r})<0.1, \mathrm{~V}(\mathrm{r}) / \rho(\mathrm{r})$ and $\mathrm{G}(\mathrm{r}) / \mathrm{V}(\mathrm{r})>1$. Electron density descriptors at the bond critical points for the significant chemical bonds of ALA@ graphene-phenyl- $\mathrm{NH}_{2}$ are showed in Table 3. Laplacian and $\mathrm{E}(\mathrm{r})$ of bonds are negative in gas and solvent phases. Moreover, the electron density values them are higher than 0.02. The analysis of quantities as $-\mathrm{G}(\mathrm{r}) / \mathrm{V}(\mathrm{r}), \mathrm{E}(\mathrm{r})$, and $\rho(r)$, showed that these bonds are covalent kind.

Table 3. Electron density descriptors (au) at the bond critical points (BCP) between atoms of ALA@ G-Phenyl-NH $\mathrm{N}_{2}$ complex

\begin{tabular}{lccccccc}
\hline Atoms & & $\rho(\mathrm{r})$ & $\nabla^{2} \rho(\mathrm{r})$ & Ellipticity & $-\mathrm{G}(\mathrm{r}) / \mathrm{V}(\mathrm{r})$ & $\mathrm{G}(\mathrm{r}) / \rho(\mathrm{r})$ & $\mathrm{E}(\mathrm{r})$ \\
\hline $\mathrm{N}_{102}-\mathrm{H}_{103}$ & Gas & 0.3480 & -1.8459 & 0.0519 & 0.0972 & 0.1599 & -0.5171 \\
\hline $\mathrm{N}_{102}-\mathrm{C}_{104}$ & Solvent & 0.3460 & -1.8586 & 0.0474 & 0.9104 & 1.4947 & -0.0509 \\
\hline \multirow{2}{*}{$\mathrm{O}_{106}-\mathrm{C}_{104}$} & Gas & 0.3146 & -0.9490 & 0.1064 & 0.3402 & 0.8025 & -0.4897 \\
\hline \multirow{2}{*}{$\mathrm{C}_{104}-\mathrm{C}_{105}$} & Solvent & 0.3157 & -0.9621 & 0.1112 & 0.3381 & 0.7959 & -0.4918 \\
\hline \multirow{2}{*}{$\mathrm{C}_{99}-\mathrm{N}_{102}$} & Gas & 0.4068 & 0.1135 & 0.0946 & 5.0987 & 1.7770 & 0.5812 \\
& Solvent & 0.3970 & 0.0223 & 0.0805 & 5.0196 & 0.2144 & 0.2269 \\
\hline
\end{tabular}


Analyzing the function of electron localization was done to corroborate the characteristics of bonds. The electron localization function(ELF) is an easy measurement of electron localization in the atomic and molecular systems. The electron localization function analysis can give information about the binding, the location of bonds, the electron pairs, the atomic structure of the system, and the strength of the bond by integrating the electron density of the ELF area. To prove the covalent bonding, the electron localization function can be utilized. ${ }^{40}$ The electron localization function amount is between zero and one. By enhancing the electron localization function, the electrons become more localized and conceptualized, the characteristics of the atomic bond between two atoms gradually transform into a covalent kind. electron localization function amounts are in the range from 0 to 1. By increasing the electron localization function, the characteristics of the bond become to covalent kind due to the electrons become more concentrated and localized. ${ }^{41}$ The topographical analysis of electron localization function of ALA@ graphene-phenyl- $\mathrm{NH}_{2}$ is done which is indicated in Figure 3 in both phases. The upper limit nelectron localization function $=1$ corresponding to perfect localization and the value electron localization function $=1 / 2$ corresponding to electrongas-like pair probability. The electron localization function for the bod between reaction ALA@ graphene-phenyl- $\mathrm{NH}_{2}$ are almost 0.42 . The electron localization function analysis characterized $\mathrm{N}-\mathrm{C}$ bonds are partly covalent that approved electron density analysis. Analyzing the natural bond orbitals prepare the electronic density distribution on atoms and bonds which is a beneficent instrument to understand the delocalization of electron density.

Table 4 indicates natural bond orbital (NBO) analysis after and before the reaction of ALA and graphene-phenyl- $\mathrm{NH}_{2}$ for main atoms in both phases. Table 4 data show that the electron densities of orbitals

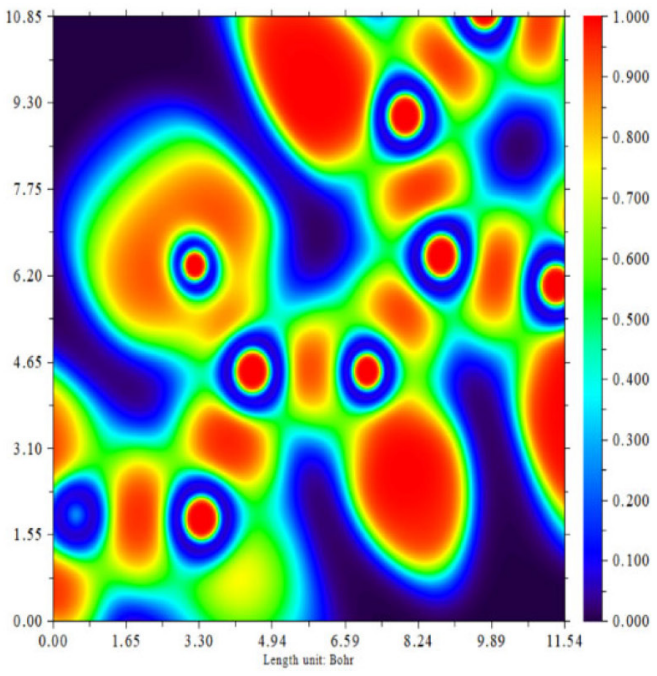

(a) have changed. The electron density of $2 \mathrm{p}$ orbitals of $\mathrm{N}_{102}$ was reduced in the gas phase while the electron density of $2 \mathrm{~s}$ was increased in the solvent phase after the reaction of ALA with graphene-phenyl- $\mathrm{NH}_{2}$. For the $\mathrm{O} 106$ atom, the electron density of $2 \mathrm{~s}$ orbital decreased after adsorption, while the electron density of the $2 p$ orbital increased in the gas phase. The electron density of $2 \mathrm{~s}$ and $2 \mathrm{p}$ orbitals decreased after the reaction in water solvent. For the $\mathrm{C} 99$ atom, the electron density of the $2 p$ orbital of $\mathrm{C} 85$ in both phases increased after reaction but the electron density of $2 \mathrm{~s}$ orbital decreased in gas phase and increased in the solvent phase. For C104 atom, the electron densities of $2 \mathrm{~s}$ and $2 \mathrm{p}$ orbitals in the solvent phase have reduced. After the reaction, the electron densities of $1 \mathrm{~s}$ orbitals of the $\mathrm{H} 103$ atom have reduced by 0.02 and 0.01 in gas and solution phases, respectively.

The advancements of Wiberg bond order can be as Mayer and Fuzzy bond order that have confirmed extremely appropriate in bonding analysis applying Mulliken population analysis and semiempirical calculation approaches. To show ALA and graphenephenyl- $\mathrm{NH}_{2}$ bonds, the bond lengths, Fuzzy bond order, and Mayer bond order were calculated as listed in Table 5. The bond length of key atoms in the solution phase increased slightly relative to the gas phase, and therefore the bond order decreased. The bond length of N102-C104 in the solution phase is shorter than the gas phase and a shorter bond length indicated a stronger bond. The amounts of MBO show that bond order reduced after the reaction in both phases. The amounts of FBO show that the bond order between the drug and the graphene-phenyl- $\mathrm{NH}_{2}$ reduced after the reaction in both phases.

The density of the states of a system is defined as the number of various states which are to be occupied by the system at every energy. The density of the states computations permit one to identify

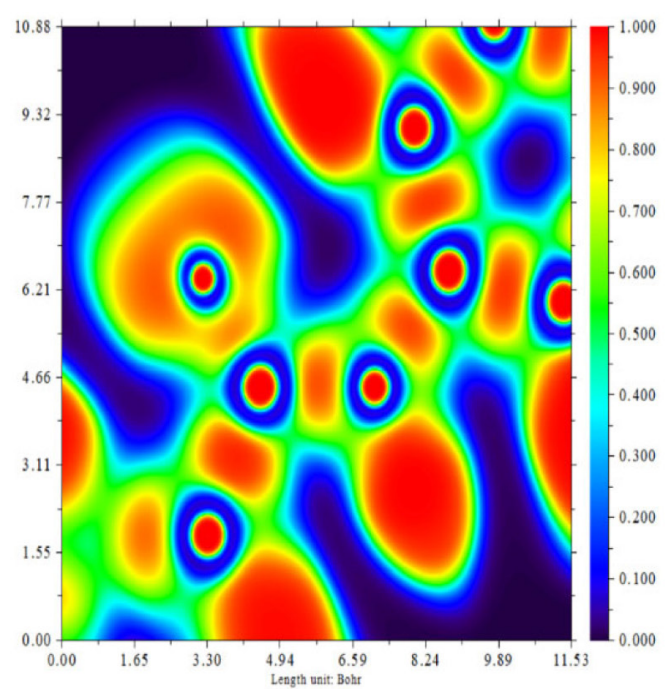

(b)

Figure 3. ELF plots of optimized ALA@G-Phenyl- $\mathrm{NH}_{2}\left({ }_{a}\right)$ at gas and $(b)$ at solvent phases

Table 4. The natural electron configuration of some atoms of the ALA and G-Phenyl- $\mathrm{NH}_{2}$ before and after reaction in gas and solvent phases

\begin{tabular}{|c|c|c|c|c|}
\hline \multirow{2}{*}{ Atoms } & \multicolumn{2}{|c|}{ Gas } & \multicolumn{2}{|c|}{ Solvent } \\
\hline & Before & After & Before & After \\
\hline $\mathrm{N}_{102}$ & $2 \mathrm{~S}^{(1.35)} 2 \mathrm{p}^{(4.50)} 3 \mathrm{p}^{(0.01)}$ & $2 \mathrm{~S}^{(1.24)} 2 \mathrm{p}^{34.40)} 3 \mathrm{p}^{(0.01)}$ & $2 \mathrm{~S}\left({ }^{(1.35}\right) 2 \mathrm{p}^{(4.51)} 3 \mathrm{p}^{(0.01)}$ & $2 \mathrm{~S}^{(1.44)} 2 \mathrm{p}^{4.22)} 3 \mathrm{p}^{(0.01)}$ \\
\hline $\mathrm{H}_{103}$ & $1 S^{(0.59)}$ & $1 S^{(0.57)}$ & $1 S^{(0.57)}$ & $1 \mathrm{~S}^{(0.56)}$ \\
\hline $\mathrm{C}_{99}$ & $2 \mathrm{~S}^{(0.84)} 2 \mathrm{p}^{(2.97)} 3 \mathrm{p}^{(0.01)}$ & $2 \mathrm{~S}^{(0.83)} 2 \mathrm{p}^{(2.99)} 3 \mathrm{p}^{(0.01)}$ & $2 \mathrm{~S}^{(0.84)} 2 \mathrm{p}^{(2.96)} 3 \mathrm{p}^{(0.01)}$ & $2 \mathrm{~S}^{(0.85)} 2 \mathrm{p}^{(2.99)} 3 \mathrm{p}^{(0.02)}$ \\
\hline $\mathrm{O}_{106}$ & $2 \mathrm{~S}^{(1.71)} 2 \mathrm{p}^{(4.89)} 3 \mathrm{~d}^{(0.02)}$ & $2 \mathrm{~S}^{(1.69)} 2 \mathrm{p}^{(4.92)} 3 \mathrm{~d}^{(0.02)}$ & $2 S^{(1.71)} 2 p\left({ }^{4.93)} 3 d^{(0.02)}\right.$ & $2 \mathrm{~S}^{(1.69)} 2 \mathrm{p}^{(4.84)} 3 \mathrm{~d}^{(0.02)}$ \\
\hline $\mathrm{C}_{104}$ & $2 \mathrm{~S}^{(0.81)} 2 \mathrm{p}^{(2.30)} 3 \mathrm{p}^{(0.03)}$ & $2 \mathrm{~S}^{(0.77)} 2 \mathrm{p}^{(2.46)} 3 \mathrm{p}^{(0.03)}$ & $2 \mathrm{~S}^{(0.81)} 2 \mathrm{p}^{(2.28)} 3 \mathrm{p}^{(0.03)}$ & $2 \mathrm{~S}^{(0.84)} 2 \mathrm{p}^{(2.42)} 3 \mathrm{p}^{(0.03)}$ \\
\hline $\mathrm{C}_{105}$ & $2 \mathrm{~S}^{(1.06)} 2 \mathrm{p}^{(3.49)} 3 \mathrm{p}^{(0.01)}$ & $2 \mathrm{~S}^{(1.05)} 2 \mathrm{p}^{(3.51)} 3 \mathrm{p}^{(0.01)}$ & $2 \mathrm{~S}^{(1.06)} 2 \mathrm{p}^{(3.50)} 3 \mathrm{p}^{(0.01)}$ & $2 \mathrm{~S}^{(1.05)} 2 \mathrm{p}^{(3.50)} 3 \mathrm{p}^{(0.01)}$ \\
\hline
\end{tabular}


Table 5. Bond distance ( $\AA$ ), Mayer bond order (MBO) and Fuzzy bond order (FBO) some of the bonds of the ALA before, and after reaction with G-Phenyl$\mathrm{NH}_{2}$ in gas and solvent phases

\begin{tabular}{|c|c|c|c|c|c|c|c|c|c|c|c|c|}
\hline \multirow{3}{*}{ Bond } & \multicolumn{4}{|c|}{ Bond Length } & \multicolumn{4}{|c|}{ MBO } & \multicolumn{4}{|c|}{ FBO } \\
\hline & \multicolumn{2}{|c|}{ Gas } & \multicolumn{2}{|c|}{ Solvent } & \multicolumn{2}{|c|}{ Gas } & \multicolumn{2}{|c|}{ Solvent } & \multicolumn{2}{|c|}{ Gas } & \multicolumn{2}{|c|}{ Solvent } \\
\hline & Before & After & Before & After & Before & After & Before & After & Before & After & Before & After \\
\hline $\mathrm{N}_{102}-\mathrm{H}_{103}$ & 1.0085 & 1.0088 & 1.0097 & 1.0111 & 0.8986 & 0.8853 & 0.8867 & 0.8741 & 0.8848 & 0.8177 & 0.8760 & 0.8078 \\
\hline $\mathrm{N}_{102}-\mathrm{C}_{104}$ & - & 1.3726 & - & 1.3718 & - & 1.0540 & - & 1.0814 & - & 1.3188 & - & 1.3353 \\
\hline $\mathrm{O}_{106}-\mathrm{C}_{104}$ & 1.2084 & 1.2185 & 1.2117 & 1.2299 & 1.8662 & 1.7821 & 1.8391 & 1.7337 & 2.0157 & 1.9541 & 1.9961 & 1.9156 \\
\hline $\mathrm{C}_{104}-\mathrm{C}_{105}$ & 1.5064 & 1.5225 & 1.5061 & 1.5254 & 0.9513 & 0.9338 & 0.9560 & 0.9398 & 1.0430 & 1.0348 & 1.0443 & 1.0348 \\
\hline $\mathrm{C}_{99}-\mathrm{N}_{102}$ & 1.3911 & 1.4077 & 1.3869 & 1.4095 & $1 / 0014$ & 0.8334 & 1.0244 & 0.8979 & 1.3387 & 1.2064 & 1.3543 & 1.2124 \\
\hline
\end{tabular}
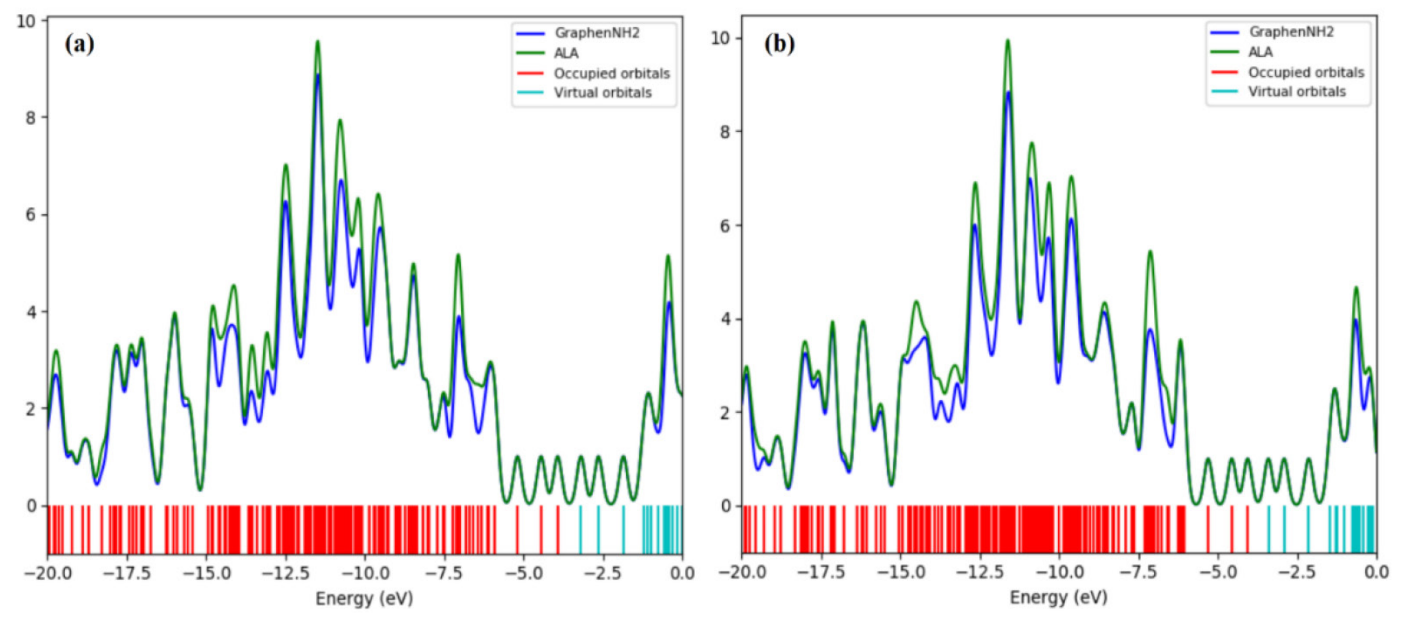

Figure 4. DOS plots of optimized ALA @ G-Phenyl-NH ${ }_{2}\left({ }_{a}\right)$ at gas and (b) at solvent phases

the general distribution of states as an energy function. The density of the states spectra help better understanding the reaction between ALA and graphene-phenyl- $\mathrm{NH}_{2}$. DOS computation showed that there is not much between ALA and graphene-phenyl- $\mathrm{NH}_{2}$ in the gas phase and the water solvent. Therefore, the difference between HOMO and LUMO energies in the two phases is low. After reaction between ALA and graphene-phenyl- $\mathrm{NH}_{2}$ (see Figure 4), the difference between HOMO energies in two phases is $0.23 \mathrm{eV}$ and also the value of $0.18 \mathrm{eV}$ for LUMO energies. Therefore, this reaction causes that in gas phase the HOMO level shifts to lower energy compared to the solvent phase, while the LUMO level is almost unchanged.

\section{CONCLUSIONS}

The density functional theory computations were done to investigate the reaction of graphene-phenyl- $\mathrm{NH}_{2}$ and ALA anticancer drug. In this article, the bond of graphene-phenyl- $\mathrm{NH}_{2}$ and ALA drug was made by an EDC/NHS cross-linking. Our studies reveal that the ALA @ graphene-phenyl- $\mathrm{NH}_{2}$ complex can adsorb more electrons in water solvent. As well, the characteristics of bonding between ALA and graphene-phenyl- $\mathrm{NH}_{2}$ is the covalent. The binding energy of ALA @ graphene-phenyl- $\mathrm{NH}_{2}$ displayed that this energy reduces from $-31.7024 \mathrm{eV}$ in the gas phase to $-35.0739 \mathrm{eV}$ in the solvent phase. Likewise, the computations of Natural bond orbital (NBO) analysis, bond lengths, Fuzzy bond order, and Mayer bond order analysis of compounds were done to approve the covalent bond. The density of the states spectra of ALA @ graphene-phenyl- $\mathrm{NH}_{2}$ have the same trends in their energy gaps in gas and solvent phases. These binding characteristics can be useful in the appropriate selection of carbon nanomaterial for targeted drug delivery.

\section{AKNOWLEDGEMENTS}

We gratefully thank Payame Noor University for financial support. The authors would like to express their appreciations to department of chemistry this university for providing research facilities.

\section{REFERENCES}

1. Raza, K.; Thotakura, N.; Kumar, P.; Joshi, M.; Bhushan, S.; Bhatia, A.; Kumar, V.; Malik, R.; Sharma, G.; Guru, S. K.; Int. J. Pharm. 2015, 495, 551.

2. Naiafi, M.; Chin. J. Struct. Chem. 2019, 38, 195.

3. Spencer, D. S.; Puranik, A. S.; Peppas, N. A.; Curr. Opin. Chem. Eng. $2015,7,84$.

4. Kamel, M.; Raissi, H.; Morsali, A.; Shahabi, M.; Appl. Surf. Sci. 2018, $434,492$.

5. Khorram, R.; Morsali, A.; Raissi, H.; Hakimi, M.; Beyramabadi, S. A.; Chin. J. Struct. Chem. 2017, 36, 1639.

6. Dass, C. R.; Su, T.; Drug Del. 2001, 8,191.

7. Dubin, C. H.; Mech. Eng. Nanotechnol. 2004, 126, 10.

8. Kuma, M. N.; J. Pharm. Pharm. Sci. 2000, 3,234.

9. Yang, K.; Feng, L.; Shi, X.; Liu, Z.; Chem. Soc. Rev. 2013,42, 530.

10. Feng, L.; Liu, Z.; Nanomedicine 2011, 6, 317.

11. Singh, S. K.; Singh, M. K.; Kulkarni, P. P.; Sonkar, V. K.; Gracio, J. J. A.; Dash, D.; ACS Nano 2012, 6, 2731.

12. Rabchinskii, M. K.; Ryzhkov, S. A.; Kirilenko, D. A.; Ulin, N. V.; Baidakova, M. V.; Shnitov, V. V.; Pavlov, S. I.; Chumakov, R. G.; Stolyarova, D. Y.; Besedina, N. A.; Shvidchenko, A. V.; Potorochin, D. V.; Roth, F.; Smirnov, D. A.; Gudkov, M. V.; Brzhezinskaya, M.; Lebedev, O. I.; Melnikov, V. P.; Brunkov, P. N.; Sci. Rep. 2020, 10, 6902. 13. Jiang, D.; J. Chem. Phys. 2007, 126, 134701. 
14. Baumgartner, R.; Pottier, R.; Krammer, B.; Stepp, H.; Photodynamic therapy with ALA, RSC Publishing: London, 2006.

15. Ishizuka, M.; Abe, F.; Sano, Y.; Takahashi, K.; Inoue, K.; Nakajima, M.; Kohda, T.; Komatsu, N.; Ogura, S.;Tanaka, T.; Int. Immunopharmacol. 2011, 11, 358 .

16. Kia, M.; Golzar, M.; Mahjoub, K.; Soltani, A.; Superlattices Microst. 2013, 62, 251

17. Samanta, P. N.; Das, K. K.; RSC Adv. 2016, 95, 92547.

18. Zaboli, M.; Raissi, H.; Rahmani Moghaddam, N.; Farzad, F.; J. Mol. Liq. 2020, 301, 112458.

19. Dastani, N.; Arab, A.; Raissi, H.; Adsorption 2020, 26, 879.

20. Shahabi, M.; Raissi, H.; J. Biomol. Struct. Dyn. 2017, 36, 2517.

21. Dastani, N.; Arab, A.; Raissi, H.; Struct. Chem. 2020, 31,1691.

22. Vovusha, H.; Banerjee, D.; Kumar Yadav, M.; Perrozzi, F.; Ottaviano, L.; Sanyal, S.; Sanyal, B.; J. Phys. Chem. C 2018, 122, 21031.

23. Ehsani, E., Shojaie, F.; J. Mol. Liq. 2021, 323, 114625.

24. Denis, P. A.; Chem. Phys. Chem. 2013, 14, 3271.

25. Denis, P. A.; Iribarne, F.; Chem. Eur. J. 2012, 18, 7568.

26. Denis, P. A.; Iribarne, F. ; J. Mater. Chem. 2012, 22, 5470.

27. Denis, P. A.; Chem. Eur. 2013, 19, 15719.

28. Denis, P. A.; Chem. Select 2017, 2, 9620.

29. Denis, P. A.; Chem. Select 2016, 1, 5497.

30. Frisch, M. J.; Trucks, G. W.; Schlegel, H. B.; Scuseria, G. E.; Robb M. A.; Cheeseman, J. R.; Scalmani, G.; Barone, V.; Petersson, G. A.; Nakatsuji, H.; Li, X.; Caricato, M.; Marenich, A. V.; Bloino, J.; Janesko, B. G.; Gomperts, R.; Mennucci, B.; Hratchian, H. P.; Ortiz, J.
V.; Izmaylov, A. F.; Sonnenberg, J. L.; Williams-Young, D.; Ding, F.; Lipparini, F.; Egidi, F.; Goings, J.; Peng, B.; Petrone, A.; Henderson, T.; Ranasinghe, D.; Zakrzewski, V. G.; Gao, J.; Rega, N.; Zheng, G.; Liang, W.; Hada, M.; Ehara, M.; Toyota, K.; Fukuda, R.; Hasegawa, J.; Ishida, M.; Nakajima, T.; Honda, Y.; Kitao, O.; Nakai, H.; Vreven, T.; Throssell, K.; Montgomery, J. A., Jr.; Peralta, J. E.; Ogliaro, F.; Bearpark, M. J.; Heyd, J. J.; Brothers, E. N.; Kudin, K. N.; Staroverov, V. N.; Keith, T. A.; Kobayashi, R.; Normand, J.; Raghavachari, K.; Rendell, A. P.; Burant, J. C.; Iyengar, S. S.; Tomasi, J.; Cossi, M.; Millam, J. M.; Klene, M.; Adamo, C.; Cammi, R.; Ochterski, J. W.; Martin, R. L.; Morokuma, K.; Farkas, O.; Foresman, J. B.; Fox, D. J.; Gaussian 09, Gaussian, Inc Wallingford, CT, 2017.

31. Lopez, N.; Illas, F.; J. Phys. Chem. B 1998, 102,1430.

32. Lu, T.; Chen, F.; J. Comput. Chem. 2012, 33, 580.

33. Mayer, I.; Salvador, P.; Chem. Phys. Lett. 2004, 383, 368.

34. Mayer, I.; Chem. Phys. Lett. 1983, 97, 270.

35. Lu, T.; Chen, F. W.; Acta Phys.-Chim. Sin. 2011, 27, 2786.

36. Lipparini, F.; Scalmani, G.; Mennucci, B.; Frisch, M. J.; J. Chem. Theory Comput. 2011, 7, 610.

37. Grimme, S.; Chem. - Eur. J. 2012, 18, 9955.

38. Bankiewicz, B.; Matczak, P.; Palusiak, M.; J. Phys. Chem. A 2011, 116, 452.

39. Jacobsen, H.; Jacobsen, H.; J. Comput. Chem. 2009, 30, 1093.

40. Becke, A. D.; Edgecombe, K. E.; J. Chem. Phys. 1990, 92, 5397.

41. Fuentealba, P.; Chamorro, E.; Santos, J. C.; Theor. Comput. Chem. 2007, $19,57$. 